\title{
Clinical efficacy and safety of fluoxetine in generalized anxiety disorder in Chinese patients
}

\author{
This article was published in the following Dove Press journal: \\ Neuropsychiatric Disease and Treatment \\ 31 October 2013 \\ Number of times this article has been viewed
}

\author{
Chuan Zou' \\ Xiang Ding' \\ Joseph H Flaherty ${ }^{2}$ \\ Birong Dong' \\ 'The Center of Gerontology and \\ Geriatrics, West China Hospital, \\ Sichuan University, Chengdu, \\ People's Republic of China; ${ }^{2}$ St Louis \\ University, St Louis, MO, USA
}

Background: Generalized anxiety disorder (GAD) is a prevalent, disabling disease and is highly comorbid with other psychiatric disorders both in Western countries and the People's Republic of China. Fluoxetine, a selective inhibitor of serotonin reuptake (SSRI), is widely utilized in the management of GAD in clinical practice despite the lack of strong evidence. This article reviews fluoxetine trials to investigate fluoxetine's efficacy and tolerability in Chinese patients with GAD.

Methods: A literature review was conducted using the following databases up to and including April 2013: Chinese BioMedical Literature, China National Knowledge Infrastructure, EMBASE, MEDLINE, and PsycINFO. We selected clinical studies that utilized fluoxetine for GAD in which all participants were Chinese.

Results: Fifteen open-label, non-placebo trials were identified and analyzed; eleven anxiolytics were compared with fluoxetine separately. Short-term efficacy of fluoxetine had been established in these open-label, head-to-head controlled trials. Fluoxetine had rapid onset of action (approximately 1-2 weeks) and seemed to be effective in maintenance treatment. Fluoxetine was generally well-tolerated with the most common side effect of dry month and nausea. Compared to other anxiolytic agents, fluoxetine was equivalent with all of the comparative anxiolytics in terms of efficacy except mirtazapine which showed conflicting results with fluoxetine in two studies. In terms of side effects, fluoxetine was better tolerated than diazepam, doxepine, and amitriptyline, less tolerated than escitalopram, and had similar tolerability with duloxetine as well as alprazolam.

Conclusion: Given the high risk of bias of the included studies, the overall small sample size of the studies, the lack of placebo control groups as well as the lack of certain clinically meaningful outcomes, it is not possible to recommend fluoxetine as a reliable first-line treatment in Chinese patients with GAD. Furthermore, no definitive implications for clinical practice in choosing anxiolytics can be drawn from this review. Trials with larger sample sizes, better quality, longer duration, and more clinically meaningful outcomes are needed in future research.

Keywords: fluoxetine, generalized anxiety disorder, clinical trials, Chinese, prevalence

\section{Introduction to the epidemiology of generalized anxiety disorder}

Generalized anxiety disorder (GAD) is a chronic disorder that is associated with a substantial degree of functional impairment, similar to that seen with major depressive disorder (MDD) ${ }^{1,2}$ It is defined in the Diagnostic and Statistical Manual of Mental Disorders - IV (DSM-IV) as "excessive anxiety and worry about a broad spectrum of events and activities that occurs on most days for at least six months. This anxiety and worry is difficult to control, and is accompanied by at least three of the 
following symptoms: difficulty concentrating, becoming easily fatigued, irritability, muscle tension, restlessness or sleep disturbance."3

GAD is common in both community and clinical settings. It is the most frequent anxiety disorder seen in primary care, with an estimated point prevalence of $5.3 \%$ of patients in this setting. ${ }^{4}$ An epidemiologic study of nationally representative samples in the United States found that prevalence rates of $12-$ month and lifetime GAD were $2.1 \%$ and $4.1 \%$, respectively. ${ }^{5}$ A recent review of epidemiological studies in Europe found 12-month prevalence rates of $1.7 \%-3.4 \%$, and lifetime prevalence rates of $4.3 \%-5.9 \%{ }^{6}$ In Australia, the estimated prevalence rate of 12 -month GAD is $3.6 \%$. ${ }^{7}$

\section{The prevalence of GAD in the People's Republic of China and associated comorbidities}

Compared with major depressive disorder, GAD is less investigated in the People's Republic of China. The prevalence of GAD was not examined in either of two national epidemiological surveys conducted in mainland People's Republic of China. However, there were epidemiological studies (list in Table 1) on GAD conducted in different areas of the People's Republic of China which provided insights into the prevalence of GAD. A recent survey carried out in five provinces of the People's Republic of China with 63,004 subjects indicated that the 1-month prevalence rate of DSM-IV GAD was $1.314 \%{ }^{8}$ Another methodologically strict study from Beijing including both rural and urban participants revealed that 1 -year and lifetime prevalence rates of GAD were as low as $0.8 \%$ and $1.2 \%$, respectively, ${ }^{9}$ which was the same as GAD statistics in metropolitan Beijing and Shanghai (0.8\% 12-month rate), ${ }^{10}$ and even higher than figures from Hebei province $\left(0.77 \%\right.$ lifetime rate). ${ }^{11}$ Compared with higher GAD prevalence around the world, authors from the above studies believed that the figures were underestimated because Chinese people may be less willing to report psychological symptoms during face-to-face interviews with health professionals due to fear of discrimination and stigmatization. Thus, by using telephone interviews, Lee et al conducted two epidemiological studies in Hong Kong communities and found a higher prevalence of GAD, $4.1 \%$ for the 6-month rate and $4.0 \%$ for the 12 -month rate. ${ }^{12,13}$ In the primary clinical setting, patients suffered from GAD with an incidence of $4.17 \%$ for the lifetime rate ${ }^{14}$ and $4.3 \%$ for the 12-month rate, ${ }^{15}$ according to two surveys. The existence of somatic symptoms made GAD patients more likely to use health care. Neurology outpatient clinics had the highest rate of GAD (11.7\%), followed by gastroenterology (9.4\%), and cardiology $(7.8 \%){ }^{14}$

In the People's Republic of China, GAD is the most common mental disease among anxiety disorders. ${ }^{8,14,16}$ Moreover, GAD is highly comorbid with other mental disorders. In one study conducted in Beijing, $80.4 \%$ of subjects with lifetime

Table I A review of epidemiological studies on GAD in the People's Republic of China

\begin{tabular}{|c|c|c|c|c|}
\hline Study & Diagnosis & Investigation site & $\begin{array}{l}\text { Subject number } \\
\text { and age }\end{array}$ & Prevalence \\
\hline \multirow[t]{2}{*}{ Phillips et a $\left.\right|^{8}$} & SCID & Qinhai, Zhejiang, Gansu, Shandong & 63,004 & $1.316 \%$ (I-month) \\
\hline & & provinces (rural and urban) & $>18 y$ & \\
\hline \multirow[t]{2}{*}{ Sun et al" } & SCID & Hebei province (rural and urban) & 24,000 & 0.77\% (lifetime) \\
\hline & & & $>18 y$ & \\
\hline \multirow[t]{2}{*}{ Chien et al ${ }^{16}$} & ICD-9 & Taiwan province (rural and urban) & $137,9 \mid 4$ & I.44\% (I2-month) \\
\hline & DSM-III & & $>18 y$ & \\
\hline \multirow[t]{2}{*}{ Ma et $\mathrm{al}^{9}$} & CIDI & Beijing city (rural and urban) & 5,926 & $0.8 \%$ (I2-month) \\
\hline & & & $>15 y$ & \\
\hline \multirow[t]{2}{*}{ Lee et $\mathrm{al}^{10}$} & CIDI & Beijing and Shanghai city (urban) & 5,201 & $0.8 \%$ (I2-month) \\
\hline & & & $18-70 y$ & \\
\hline \multirow[t]{2}{*}{ Lee et $\mathrm{al}^{12}$} & DSM-IV & Hong Kong city (urban) & 3,304 & $4.1 \%$ (6-month) \\
\hline & & & $15-60 y$ & \\
\hline \multirow[t]{2}{*}{ Lee et $\mathrm{al}^{13}$} & DSM-IV & Hong Kong city (urban) & 2,005 & $4.0 \%$ (I2-month) \\
\hline & & & $15-60 y$ & \\
\hline \multirow[t]{2}{*}{ Ying et $\mathrm{al}^{15}$} & DSM-IV & Shanghai city (out patients in 4 primary & 3,073 & $4.3 \%$ (I2-month) \\
\hline & & care facilities) & $>18 y$ & \\
\hline \multirow[t]{2}{*}{ He et $\mathrm{al}^{14}$} & MINI & Beijing, Guangzhou, Shanghai, Changsha, & 8,487 & $4.17 \%$ (lifetime) \\
\hline & & Chengdu cities (in 15 hospitals) & $>18 y$ & \\
\hline
\end{tabular}

Abbreviations: GAD, generalized anxiety disorder; SCID, Structured Clinical Interview for DSM-IV; CIDI, Composite International Diagnostic Interview; DSM-IV, Diagnostic and Statistical Manual for Mental Disorders, Fourth Edition; DSM-III-R, Diagnostic and Statistical Manual of Mental Disorders, Third Edition, Revised; ICD-9, International Classification of Diseases-9; MINI, Mini International Neuropsychiatric Interview; $y$, years old. 
GAD met criteria for another psychiatric disorder, ${ }^{9}$ a figure in line with previous findings of $66 \%-93 \%$ in other developed countries. ${ }^{17,18}$ In addition, GAD has a strong association with major depressive disorder (MDD), ranging from $59 \%-72 \%$ in different Chinese surveys, ${ }^{9,12,14,15}$ as well as substance abuse $(35 \%)$ in a Hong Kong study, ${ }^{15}$ and other anxiety disorders $(24.8 \%) .{ }^{14}$ Data using the Sheehan disability scale showed that comorbidity of GAD and other mental disorders had greater impact on patients' quality of life than pure GAD. ${ }^{14}$

\section{Review of pharmacological approaches for the treatment of GAD}

The main goals of pharmacotherapy in treating generalized anxiety disorder are to reduce anxiety, improve quality of life with minimum adverse effects, treat comorbid disorders, such as depression or substance dependence, and prevent relapse. Currently, there are a variety of drug choices used to treat GAD with different degrees of evidence and recommendation according to domestic and international guidelines. ${ }^{19,20}$

Selective serotonin-reuptake inhibitors (SSRIs) such as paroxetine, sertraline, and escitalopram and serotoninnorepinephrine reuptake inhibitors (SNRIs) like venlafaxine and duloxetine have well-documented efficacy for GAD in both short-term treatment and long-term relapse prevention. ${ }^{20}$ Common side effects of both SSRIs and SNRIs include sexual dysfunction, nausea, insomnia, agitation, and withdrawal symptoms as well as drug interaction. However, most adverse events are generally mild or moderate in severity and tend to be of short duration. Due to their combined efficacy, safety, and tolerability, SSRIs and SNRIs are generally regarded as first-line medications. ${ }^{19,20}$

Second-line medications for GAD include benzodiazepines, buspirone, pregabalin, and tricyclic antidepressants. Benzodiazepines have rapid onset of action in reducing emotional and somatic symptoms in GAD and have shown equal efficacy with SSRIs ${ }^{21}$ in short-term treatment. However, the likelihood of dependence, the incidence of rebound anxiety after withdrawal, and the sedative adverse effects have rendered benzodiazepines to the acute phase of anxiety before SSRIs or SNRIs take effect. Similar to benzodiazepine, buspirone is another anxiolytic indicated for the short-term relief of the anxiety symptoms for GAD but with clearly slower onset of action (3-4 weeks) and less effectiveness than benzodiazepines in a systematic review. ${ }^{22}$ However, the merits of this drug over benzodiazepines is that it lacks the adverse events of sedation, discontinuation symptoms, and dependence. Pregabalin, an anticonvulsant agent, is another fast-action anxiolytic (about 2 weeks) demonstrating moderate benefit in terms of Hamilton rating scale for anxiety (HAM-A) scores and is proving to be better than benzodiazepines with regards to efficacy and tolerability. ${ }^{23}$ Among tricyclic antidepressants, only imipramine has shown clinical efficacy for GAD. ${ }^{24}$

New pharmacological approaches such as secondgeneration antipsychotic medications (SGAs) are applied in clinical practice for treatment-resistant GAD patients who do not respond to first-line or second-line therapy. However, a systematic review of five randomized controlled trials (RCTs) with refractory GAD failed to support SGAs augmentation. Moreover, augmentation was correlated with a higher discontinuation rate because of adverse effects, including weight gain, sedation, and tardive dyskinesia. ${ }^{25}$ Hydroxyzine, however, appeared effective for GAD over placebo and seemed equivalent with other anxiolytic agents (benzodiazepines and buspirone); the analysis suggested a high risk of bias. ${ }^{26}$ Therefore, SGAs and hydroxyzine should only be considered for GAD after safer and reliable anxiolytics have been exhausted.

In the People's Republic of China, the literature on pharmacotherapy in Chinese patients with GAD is plentiful, but almost all of them are open-label, non-placebo trials with small numbers of participants, except for one randomized, double-blind study exploring the efficacy of duloxetine. ${ }^{27}$ Moreover, none of the cross-culture studies investigating the efficacy of any anxiolytics in GAD enrolled Chinese GAD subjects. Therefore, Chinese psychiatrists prefer to adopt the suggestions from the guidelines of Western countries and make the pharmaceutical options for Chinese GAD patients based on foreign literature rather than literature of our own.

\section{Comparative safety, tolerability, and efficacy of fluoxetine for the treatment for GAD Background}

Fluoxetine was first introduced into clinical use for the treatment of patients with depression in 1988. Since its release, fluoxetine has become the most widely prescribed antidepressant drug in the world. It was also approved in the following years for use in the treatment of patients with other indications, including obsessive compulsive disorder, bulimia nervosa, premenstrual dysphoric disorder, as well as major depression in children and adolescents.

Fluoxetine is a kind of SSRI and occupies the serotonin transporter with high affinity and specificity, thereby 
demonstrating anti-anxiety effects by increasing the length of time that serotonin is available in the synapse and increasing postsynaptic serotonin receptor occupancy. In addition, recent studies have provided evidence suggesting that fluoxetine may normalize the decreased brain levels of neuroactive GABAergic steroids such as allopregnanolone, which are reduced in patients with depression and post-traumatic stress disorders (PTSD). ${ }^{28,29}$ Preclinical studies using socially isolated mice which resembled some of the symptoms observed in PTSD patients demonstrated that fluoxetine and its metabolite improved anxiety-like behavior and fear responses by increasing the biosynthesis of allopregnanolone in various brain regions. ${ }^{30,31}$ These studies provided evidence suggesting that fluoxetine played the anxiolytic effects by acting as as the role of selective brain steroidogenic simulants (SSBSs) that may be independent from modifications of 5-HT reuptake mechanisms. ${ }^{30,32}$

In terms of treatment efficacy for GAD, fluoxetine ranked first out of nine anxiolytics for response and remission in a systematic review of 27 RCTs. However, this result was analyzed from only one RCT. ${ }^{32}$ In another double-blind, placebo-controlled study of subjects with GAD and comorbid MDD, the response rate of the fluoxetine group was merely $45 \%$ compared with $24 \%$ in the placebo group. ${ }^{35}$ Overall, the effectiveness and tolerability of fluoxetine on GAD were based on limited data and clinical experience in Western countries, thereby making fluoxetine a second choice when choosing SSRIs for GAD.

As for Chinese patients with GAD, fluoxetine is also not approved by the China Food and Drug Administration due to its insufficient evidence of efficacy both on Westerners and Chinese. Furthermore, a number of studies have shown that serotonin transporter (5-HTT) variation in genotypes were associated with different efficacy/response to SSRIs in both depression and GAD. ${ }^{33,34}$ A meta-analysis has demonstrated the long variant of the serotonin transporter gene, which leads to higher expression of brain 5-HTT compared to the deletion variant (short allele). It had a clear antidepressant effect in Caucasians, but had only a small effect in Asians. ${ }^{34}$ Moreover, the long allele is much less frequent in Asians as opposed to Western populations and the $\mathrm{s} / \mathrm{s}$ (short/short) genotype is more commonly varied between $55.6 \%$ and $60.0 \%$ in studies with Asian patients compared to Western studies, which varied from $21.6 \%$ to $28.3 \%{ }^{35}$ This was consistent with a Chinese GAD study that showed that the frequency of the s/s genotype was $68 \% .{ }^{36}$ Due to the above genetic variation, Asian patients with GAD might have poorer response to SSRIs; this hypothesis was supported by a pooled analysis which showed paroxetine, another SSRIs, had the lowest response and remission rate for anxiety disorders in Asian patients compared to other ethnic groups like White, Black, and Hispanics. ${ }^{37}$

From the pharmacokinetic point of view, fluoxetine is well absorbed after oral administration, reaching peak plasma concentrations after 6-8 hours and having an elimination half-life of 4-6 days. It is metabolized to another active derivate, nor-fluoxetine, by the cytochrome P450s (CYPs) in hepatic microsomes mainly via CYP2D6 and CYP2C19. However, previous studies showed ethnic variation between Asian and Western populations existed in the distribution of both CYP2D6 and CYP2C19 polymorphisms. ${ }^{38-40}$ As an example, significantly higher frequencies of the CYP2C19poor metabolic genotypes were observed in Chinese Han (18.7\%) subjects than has been reported for Caucasians $(1.7 \%-3.0 \%) .{ }^{39}$ As the CYP2C19 played an important role in the metabolism of fluoxetine reported in Chinese subjects, ${ }^{41,42}$ it can be inferred that poor metabolizers of fluoxetine are more prevalent in the Chinese population as opposed to in Caucasians.

Therefore, taking these ethnic differences into account, Chinese patients with GAD taking the same dose of fluoxetine as Westerners might exhibit completely different pharmacodynamics, pharmacokinetics, as well as diverse side effects than from Westerners. Thus, in the following part of this article, we aim to investigate fluoxetine's efficacy and tolerability in Chinese patients with GAD.

\section{Method}

We conducted a search of the following databases: Chinese BioMedical Literature (January 1978-April 2013), China National Knowledge Infrastructure (January 1979April 2013), EMBASE (January 1974-April 2013), MEDLINE (January 1966-April 2013), and PsycINFO (January 1988-April 2013). Our search was performed using the following keywords: 'anxiety disorder', 'general anxiety disorder', or 'GAD', combined with 'fluoxetine'. We selected controlled clinical trials allocating Chinese patients with GAD to fluoxetine versus placebo and/ or any other anxiolytic agent. Overlapping articles were excluded.

\section{Results}

We found a total of 15 reports of fluoxetine studies of GAD fitting our defined criteria. All publications have been copyrighted and published openly in the People's Republic of China. All of the studies were randomized, open-label, 
head-to-head clinical trials comparing fluoxetine with other anxiolytics without a placebo arm, except one study investigating the efficacy of fluoxetine with a different schedule.

As shown in Table 2, all studies involved adults who had a Chinese classification of mental disorders of 2, 3, or DSM-IV diagnosis of GAD. The HAM-A score was not only used as the selection criteria $(>14)$, but was also utilized as the primary efficacy measurement at each visit compared with baseline. In contrast to Western researchers who define response as a change from baseline to endpoint in the HAM-A total score of $50 \%$ or greater and remission as seven or less at endpoint, Chinese researchers classify the efficacy into four grades by using the HAM-A score change: recovery ( $\geq 75 \%$ ), marked improvement (50\%-74\%), sustained improvement
( $25 \%-49 \%)$, and non-response $(<25 \%)$. In order to be consistent with Western data, we calculated the response rate by adding the recovery rate and marked improvement rate within the articles. In addition, a number of other endpoints relating to HAM-A psychological and somatic anxiety factor scores, self-rating anxiety scale (SAS), Hamilton rating scale for depression (HAM-D), self-rating depression scale (SDS), and clinical global impressions of severity (CGI-S) score were also assessed in some studies.

In terms of safety and tolerability, adverse effects were monitored and evaluated by the treatment emergent symptom scale (TESS) in these studies, which is designed to assess possible treatment-related symptoms of different physical systems. The severity is divided into five degrees from 0 (no

Table 2 Efficacy studies of fluoxetine in treatment of Chinese patients with GAD

\begin{tabular}{|c|c|c|c|c|c|c|c|c|}
\hline Study & $\begin{array}{l}\text { Treatment } \\
\text { arms }\end{array}$ & $\begin{array}{l}\text { Numberl } \\
\text { \%female }\end{array}$ & Diagnosis & $\begin{array}{l}\text { Treatment } \\
\text { length }\end{array}$ & $\begin{array}{l}\text { Baseline } \\
\text { HAM-A }\end{array}$ & $\begin{array}{l}\text { Endline } \\
\text { HAM-A }\end{array}$ & $\begin{array}{l}\text { Response } \\
\text { rate }\end{array}$ & $\begin{array}{l}\text { Recovery } \\
\text { rate }\end{array}$ \\
\hline \multirow[t]{2}{*}{ Shao et $\mathrm{al}^{44}$} & F: fluoxetine & F: $3 \mathrm{I} / 58 \%$ & CCMD-3 & 4 weeks & NR & NR & $\mathrm{F}: 74 \%$ & NR \\
\hline & C: escitalopram & C: $31 / 61 \%$ & & & & & C: $77 \%$ & \\
\hline \multirow[t]{2}{*}{ Li et $\mathrm{al}^{43}$} & F: fluoxetine & F: $30 / 56 \%$ & CCMD-3 & 8 weeks & $F: 25.0 \pm 4.16$ & $F: 8.28 \pm 3.65$ & $\mathrm{~F}: 73.3 \%$ & $\mathrm{~F}: 43 \%$ \\
\hline & C: escitalopram & C: $30 / 46 \%$ & & & C: $24.9 \pm 4.71$ & $C: 8.25 \pm 3.12$ & C: $76.7 \%$ & C: $50 \%$ \\
\hline \multirow[t]{2}{*}{ Tang et $\mathrm{al}^{45}$} & F: fluoxetine & $F: 30 / 33 \%$ & CCMD-3 & 6 weeks & $F: 23.8 \pm 4 . I$ & $\mathrm{~F}: 9.8 \pm 2.4$ & $\mathrm{~F}: 83.3 \%$ & $\mathrm{~F}: 56.6 \%$ \\
\hline & C: duloxetine & C: $30 / 42 \%$ & & & $C: 25.1 \pm 3.7$ & $C: 9.7 \pm 2.1$ & C: $80.0 \%$ & C: $60 \%$ \\
\hline \multirow[t]{2}{*}{ Peng et $\mathrm{al}^{50}$} & F: fluoxetine & F: $31 / 58 \%$ & CCMD-3 & 6 weeks & F: $28.5 \pm 7.3$ & $\mathrm{~F}: \mathrm{II} . \mathrm{I} \pm 5.4$ & F: $70.9 \%$ & F: $35.4 \%$ \\
\hline & C: aprazolam & C: $29 / 58 \%$ & & & C: $28.3 \pm 6.9$ & C: $11.8 \pm 6.3$ & C: $68.9 \%$ & C: $31.0 \%$ \\
\hline \multirow[t]{2}{*}{ Sun et $\mathrm{al}^{48}$} & F: fluoxetine & F: $46 / 52 \%$ & CCMD-2-R & 8 weeks & $\mathrm{F}: 30.2 \pm 9.8$ & $\mathrm{~F}: 10.4 \pm 1 \mathrm{I} .6$ & F: $67.3 \%$ & $\mathrm{~F}: 32.6 \%$ \\
\hline & C: diazepam & C: $40 / N R$ & & & C: $32.6 \pm 9.6$ & C: $11.6 \pm 11.8$ & C: $67.5 \%$ & C: $30.0 \%$ \\
\hline \multirow[t]{2}{*}{ Liu et $\mathrm{al}^{49}$} & F: fluoxetine & F: $56 / 42 \%$ & CCMD-3 & 4 weeks & F: $32.8 \pm 9.7$ & $F: 7.6 \pm 3.1$ & $\mathrm{~F}: 78.5 \%$ & $\mathrm{~F}: 46.4 \%$ \\
\hline & C: diazepam & C: $56 / 39 \%$ & & & C: $31.6 \pm 10.3$ & $C: 9.8 \pm 5.3$ & C: $76.7 \%$ & C: $41.0 \%$ \\
\hline \multirow[t]{2}{*}{ He et $\mathrm{al}^{51}$} & F: fluoxetine & F: 26/NR & CCMD-II-R & 4 weeks & $F: 28.3 \pm 6.3$ & $F: 12.3 \pm 4.8$ & $\mathrm{~F}: 38.5 \%$ & NR \\
\hline & C: duoxepine & C: $32 / N R$ & & & C: $27.9 \pm 5.8$ & C: $11.9 \pm 3.9$ & C: $53.1 \%$ & \\
\hline \multirow[t]{2}{*}{ Chen et $\mathrm{al}^{53}$} & F: fluoxetine & F: $55 / 45 \%$ & CCMD-3 & 8 weeks & NR & NR & $\mathrm{F}: 72.7 \%$ & $\mathrm{~F}: 45.4 \%$ \\
\hline & C: mirtazapine & C: $55 / 47 \%$ & & & & & C: $56.3 \% *$ & C: $36.3 \%$ \\
\hline \multirow[t]{2}{*}{ Niu et $\mathrm{al}^{54}$} & F: fluoxetine & F: 35/7I\% & DSM-IV & 8 weeks & $F: 22.0 \pm 5.0$ & $F: 8.0 \pm 3.0$ & F: $89.0 \%$ & NR \\
\hline & C: mirtazapine & C: $35 / 65 \%$ & & & $C: 23.0 \pm 5.0$ & $C: 7.0 \pm 3.0$ & C: $94.0 \% *$ & \\
\hline \multirow[t]{2}{*}{ Wu et $a^{55}$} & F: fluoxetine & F: 29/NR & CCMD-3 & 6 weeks & NR & NR & $F: 65.5 \%$ & NR \\
\hline & C: bupropion & C: $30 / N R$ & & & & & C: $66.6 \%$ & \\
\hline \multirow[t]{2}{*}{ Tu et $a^{56}$} & F: fluoxetine & F: $4 \mathrm{I} / 36 \%$ & DSM-IV & 4 weeks & F: $28.6 \pm 12.4$ & $\mathrm{~F}: 10.2 \pm 4.67$ & $F: 65.8 \%$ & F: $24.3 \%$ \\
\hline & C: deanxit ${ }^{b}$ & C: $4 I / 44 \%$ & & & C: $29.1 \pm 11.9$ & $C: 10.7 \pm 5.03$ & C: $58.5 \%$ & C: $19.5 \%$ \\
\hline \multirow[t]{2}{*}{ Zhen et $\mathrm{al}^{57}$} & F: fluoxetine & F: $30 / 56 \%$ & CCMD-2-R & 8 weeks & $F: 27.6 \pm 9.4$ & $F: 10.4 \pm 7.4$ & F: $70.0 \%$ & F: $33.3 \%$ \\
\hline & C: buspirone & C: $30 / 63 \%$ & & & $C: 26.5 \pm 10.1$ & C: $10.3 \pm 6.5$ & C: $80.0 \%$ & C: $30.0 \%$ \\
\hline \multirow[t]{2}{*}{ Liu et $\mathrm{a}^{65}$} & F: fluoxetine & $\mathrm{F}: 42 / 57 \%$ & DSM-IV & 8 weeks & $F: 26.7 \pm 3.8$ & $F: 13.9 \pm 3.1$ & $\mathrm{~F}: 41.9 \%$ & NR \\
\hline & $C: F+o^{\prime a n z a p i n e}{ }^{c}$ & C: $96 / 61 \%$ & & & $C: 27.4 \pm 3.6$ & C: $7.6 \pm 3.2^{*}$ & C: $95.6 \% *$ & \\
\hline \multirow[t]{2}{*}{ Ma et $\mathrm{al}^{59}$} & F: fluoxetine qd & F: $33 / 57 \%$ & CCMD-2-R & 3 months & $F: 8.96 \pm 3.14$ & $F: 9.66 \pm 4.19$ & NR & NR \\
\hline & C: fluoxetine qw & C: $31 / 61 \%$ & & & C: $8.40 \pm 3.53$ & C: $9.59 \pm 4.69$ & & \\
\hline \multirow[t]{3}{*}{$X u$ et $\left.a\right|^{52}$} & F: fluoxetine & $F: 25 / 76 \%$ & DSM-IV & 8 weeks & $F: 45.8 \pm 7.3^{e}$ & $F: 30.4 \pm 11.2^{\mathrm{e}}$ & NR & NR \\
\hline & C: amitriptyline & C: $24 / 70 \%$ & & & $C: 46.5 \pm 8.2$ & $C: 29.8 \pm 10.6$ & & \\
\hline & $M: F+C^{d}$ & & & & M: $46.0 \pm 7.7$ & M: $22.3 \pm 9.8^{*}$ & & \\
\hline
\end{tabular}

Notes: Response rate: more than $50 \%$ reduction of HAM-A scores from baseline to endpoint; recovery rate: more than $75 \%$ reduction of HAM-A scores from baseline to endpoint. aAll of the included trials were open-label, non-placebo studies; beach combined pill contained $0.5 \mathrm{mg}$ flupentixol and $10 \mathrm{mg}$ melitracen; 'this arm was adminstered $20 \mathrm{mg}$ fluoxetine for 8 weeks and $5 \mathrm{mg}$ olanzapine for the initial 2 weeks; ${ }^{\mathrm{d}}$ this arm was administered $20 \mathrm{mg}$ fluoxetine and $37.5 \mathrm{mg}$ amitriptyline; ${ }^{\mathrm{e}}$ the scores in this trial were measured by SAS; *statistical difference $(P<0.05)$ between this arm and fluoxetine arm.

Abbreviations: GAD, generalized anxiety disorder; F, fluoxetine arm; C, control arm; M, mixed drug arm; NR, not reported; DSM-IV, Diagnostic and Statistical Manual for Mental Disorders, Fourth Edition; CCMD-2, Chinese Classification and Diagnostic Criteria of Mental Disorders 2nd version revised; CCMD-3, Chinese Classification and Diagnostic Criteria of Mental Disorders 3rd version; HAM-A, Hamilton anxiety rating scale; SAS, self-rating anxiety scale. 
symptom) to 4 (severe) and adverse effects were defined as a score $>1$. In addition, blood chemistry, hematology, and urinalysis were also carried out at the baseline and endpoint visits in most studies.

\section{Short-term efficacy of fluoxetine}

We describe the results of these head-to-head studies in the following sections according to the drug class with which fluoxetine is compared: SSRI and SNRI, benzodiazepine, TCA, atypical antidepressants, and others.

There were two articles comparing fluoxetine with escitalopram and one article with duloxetine. In the first controlled study, each group had 30 GAD subjects without depression. HAM-A scores decreased to $8.28 \pm 3.65$ after 8 weeks' treatment of $20-40 \mathrm{mg}$ fluoxetine from $25.03 \pm 4.16$ at baseline, whereas the 10-20 mg escitalopram group dropped from $24.98 \pm 4.71$ to $8.25 \pm 3.12$. There was no difference found in the reduction of anxiety at the completion of the study. Both groups showed a similar response rate $(73.3 \%$ for fluoxetine, $76.7 \%$ for escitalopram) and recovery rate (43\% and 50\%, respectively). ${ }^{43}$ In another 4 -week clinical trial conducted by Shao et al, there was also no difference between fluoxetine and escitalopram in their response rates (74\% and $77 \%$, respectively) and remission rates $(19 \%$ and $16 \%$, respectively). ${ }^{44}$ In contrast to duloxetine, Tang et al reported that fluoxetine showed equivalent efficacy either on HAM-A scores' reduction or response rate at the end of a 6-week trial. ${ }^{45}$ These results were consistent with several RCTs in Western countries that directly compared different SSRIs and SNRIs, in which no statistically significant difference was found between them. ${ }^{46,47}$ Although there is less available data, it implies that fluoxetine can also be utilized as an effective SSRI in treating GAD.

Compared with benzodiazepines, fluoxetine also demonstrated similar efficacy in Chinese patients based on three clinical trials, two of which had were compared with diazepam, and one with alprazolam. Sun et al reported that $67 \%$ of GAD participants had reached clinical response in both fluoxetine and diazepam groups after 8 weeks' treatment, ${ }^{48}$ while in another study with 56 participants in each arm, the number of participants reaching clinical response after 4 weeks' therapy was rather close, 44 and 43, respectively. ${ }^{49}$ The third study with alprazolam also showed no statistical difference on endpoint HAM-A scores $(11.1 \pm 5.4$ for fluoxetine versus $11.8 \pm 6.3$ for aprazolam), as well as recovery rate. ${ }^{50}$

Two clinical trials were conducted separately comparing fluoxetine with tricyclic antidepressants (TCA) including doxepine and amitriptyline. In a 4-week trial comparing treatment with doxepine and fluoxetine, both groups showed significant reduction in comparison with baseline on total HAM-A scores and no significant difference $(P>0.05)$ was found between the two groups. As for response rates, doxepine seemed superior to fluoxetine with $53.1 \%$ versus $38.3 \%$ but without a statistically significant difference (RR 1.813, 95\% CI: 0.633-5.191). ${ }^{51}$ In another study, 72 participants with comorbid GAD and MDD were randomly divided into three arms, fluoxetine (20 mg/day), amitriptyline (50 mg/day tid), and combined therapy (fluoxetine $20 \mathrm{mg} /$ day + amitriptyline $12.5 \mathrm{mg}$ tid). Both SAS and SDS were measured for the enrolled subjects before and post the treatment. After 8 weeks' treatment, the monotherapy arms demonstrated similar effectiveness on both anxiety and depression symptoms, while the combined therapy arm showed significantly larger effect. Taking SAS scores for example, the endpoint scores were $30.4 \pm 11.2$ for fluoxetine, $29.8 \pm 10.6$ for amitriptyline, and $22.3 \pm 9.8$ for the combined arms. ${ }^{52}$

Two atypical antidepressant drugs, mirtazapine and bupropion, were investigated separately with regard to their comparative efficacy with fluoxetine. Chen et al revealed that mirtazapine was inferior to fluoxetine in treating GAD, since the response rate of mirtazapine was only $56.36 \%$ in contrast to $72.72 \%$ for fluoxetine $(P<0.05) .{ }^{53}$ On the other hand, both mirtazapine and fluoxetine presented significant efficacy on HAM-A reduction without significant difference after 8 weeks' treatment in participants in a study with GAD and comorbid MDD. ${ }^{54} \mathrm{Wu}$ et al conducted a study suggesting that bupropion might have equal efficacy with fluoxetine, for which the mean change of HAM-A scores from baseline to endpoint were $8.80 \pm 5.59$ and $8.79 \pm 5.31$, respectively. In addition, both groups had similar mean CGI-S changes and response rates at the completion of the trial. ${ }^{55}$ Another study comparing fluoxetine with a combined tablet of flupentixol and felitracen, which was indicated for depression, also showed no difference on treating GAD patients. ${ }^{56}$

In terms of efficacy between fluoxetine and buspirone, Zhen et al suggested that they may have similar effect on both HAM-A score reduction and subscale score of psychological symptoms and somatic symptoms after 8 weeks' treatment. In addition, the response rates were $70 \%$ for fluoxetine versus $80 \%$ for buspirone without statistical difference. ${ }^{57}$

In summary, fluoxetine has been shown to be efficacious in Chinese patients with GAD in short-term treatment, since most of the studies had showed that the response rate in fluoxetine arms was more than $70 \%$, and the recovery rate was between $30 \%$ and $50 \%$. However, a placebo effect cannot be 
excluded. Although most of the trials came to the conclusion that there were no statistically significant differences in terms of efficacy between fluoxetine and certain anxiolytics, whether fluoxetine is equivalent with anxiolytics in treating GAD is uncertain due to the limitations of these studies. The first significant limitation is the statistical method. The best way to investigate relative effectiveness of different medications is non-inferiority testing rather than superiority testing which cannot conclude the two medications have similar efficacy within a certain margin. Another limitation relates to the issue of sample size. Most of these studies had insufficient patient numbers to analyse with the purpose of making a conclusion about which drug is better. Therefore, no definitive implication of drug options for clinical practice can be drawn.

\section{Time course of change}

The time course of symptom relief has attracted clinical interest in the treatment of GAD. Data had shown that early symptomatic improvement can be a useful indicator of eventual clinical response, ${ }^{58}$ and therefore can be used to guide clinical decision making. Moreover, many clinicians believe that quicker onset of action can help maintain treatment adherence. Thus, the time course of change was evaluated in many fluoxetine treatment trials. In two of these studies, the statistically significant difference between HAM-A at baseline and HAM-A at follow-up visits was evident as early as week $1(P \leq 0.01)$ and remained significant at all subsequent visits. ${ }^{45,54}$ In another five studies, the differences between HAM-A at baseline and HAM-A at follow-up visits were statistically significant $(P \leq 0.01)$ at week 2 and remained significant at all subsequent visits. ${ }^{48,50-52,54}$ Only one study demonstrated that the acting time of fluoxetine was as long as 4 weeks. ${ }^{43}$ Although the early onset of fluoxetine had been observed in the above trials, no researcher investigated the association between the early response to fluoxetine and final efficacy by the end of the treatment. In comparison with other analytics in Chinese studies, fluoxetine had a similar acting time to duloxetine,${ }^{45}$ alprazolam, ${ }^{50}$ diazepam, ${ }^{48}$ as well as buspirone, ${ }^{57}$ doxepine,${ }^{51}$ and mirtazapine,${ }^{54}$ while faster than flupentixol and melitracen, ${ }^{56}$ but slower than escitalopram. ${ }^{43}$

\section{Maintenance treatment of fluoxetine}

Although fluoxetine had shown its efficacy in the short-term treatment of GAD, no RCT currently exists in Western countries on the effect of long-term efficacy. A Chinese study had been carried out to compare the efficacy of daily dosing and once-weekly dosing of fluoxetine in the maintenance treatment of GAD. In the baseline assessment phase, all subjects $(\mathrm{N}=64)$ had responded positively to an open-label trial of $20 \mathrm{mg}$ fluoxetine daily after at least 1 month of treatment. In the follow-up phase, patients were randomly assigned to once-weekly or once-daily fluoxetine for 3 months. The result showed that there were no significant differences in HAM-A scores in and between the two groups before or after the maintenance treatment. ${ }^{59}$ It suggested that $20 \mathrm{mg}$ fluoxetine is also effective for maintaining the efficacy of GAD. Moreover, the fluoxetine dose can be switched to once a week after clinical remission due to its long half-life. This has also been shown in depression ${ }^{60}$ and panic disorder. ${ }^{61}$ Recently, a once-weekly enteric-coated formulation of $90 \mathrm{mg}$ fluoxetine has been made available and had an equivalent efficacy and safety profile to daily fluoxetine in maintenance treatment in depression. ${ }^{62}$ However, its efficacy on GAD remains unknown and needs further research.

\section{Treatment of GAD comorbid with MDD}

Depression is the most common comorbidity in GAD patients in clinical practice, and may result in greater symptom severity and poorer treatment response than either condition alone. A Chinese study demonstrated that anxious, depressed patients have poorer outcomes to drug remission than nonanxious, depressed patients. ${ }^{63}$ Similarly, this may be part of the reason for treatment-resistant GAD leading to adjuvant therapy. Although SSRIs have shown efficacy in each disorder individually, data are limited to support their efficacy in both disorders when they occur comorbidly. As for fluoxetine, a subanalysis of RCTs in Canada showed that the response rates for co-occurring GAD and MDD after 12 weeks of fluoxetine treatment were $52 \%$ and $45 \%$, respectively, in contrast to placebo ( $36 \%$ and $24 \%$, respectively). ${ }^{64}$ In the People's Republic of China, only three of the selected studies enrolled Chinese participants with both GAD and MDD. In Niu's study, apart from significantly reducing HAM-A scores, both mirtazapine and fluoxetine demonstrated similar efficacy on HAM-D reduction at the end of treatment. ${ }^{54}$ In another comparative study of fluoxetine and amitriptyline, approximately $70 \%$ reduction of SAS and SDS scores had been observed in two monotherapy arms, while in combination arms, the proportion increased to more than $90 \% .^{52}$ The combined efficacy seemed superior to fluoxetine alone in treating co-occurring conditions. This was also supported by another olanzapine augmentation study that showed the response rates of GAD and MDD in the fluoxetine/olanzapine group were as high as $95.6 \%$ and $96.4 \%$, respectively, while 
the fluoxetine monotherapy groups were only $41.9 \%$ and $42.0 \%$, respectively. However, the augmentation group was associated with higher likelihood of adverse effects, including somnolence and dizziness. ${ }^{65}$

\section{Tolerability and safety}

Table 3 presents pooled data on adverse events in the above eleven GAD studies of fluoxetine arms by TESS. $^{43,44,48,50,51,54-56,59,65}$ Overall, the types of adverse events evident for fluoxetine in the treatment of GAD were similar to those arising in the treatment of other indications for fluoxetine. The most common adverse events were dry mouth and nausea, followed by insomnia, drowsiness, constipation, and agitation. Since TESS do not contain the items for sexual dysfunction, it was seldom reported, with only two cases in Peng's study. ${ }^{50}$ Among the total of 436 participants receiving fluoxetine, there were only two participants who reported discontinuing the fluoxetine therapy owing to adverse events of gastrointestinal reaction. ${ }^{43,54}$ According to these studies, events related to active treatment were generally mild to moderate in severity, occurred early in the course of treatment, and tended to resolve with continued treatment. Few clinically serious adverse events or changes in laboratory results, vital signs, weight, or ECG were noted in fluoxetine arms.

Compared with other analytics, fluoxetine has been shown to be less tolerable than escitalopram, with significantly more adverse events in both controlled trials $\left(\chi^{2}=4.993, P<0.05\right) .{ }^{43,44}$ However, both fluoxetine and duloxetine had similar numbers of adverse events (six for fluoxetine versus seven for duloxetine). ${ }^{51}$ In contrast to benzodiazepines, fluoxetine-treated patients in three studies were more likely to have nausea, dry mouth, and insomnia, while benzodiazepines-treated patients tended to have fatigue, drowsiness, and somnolence. The risk of adverse events for alprazolam in Peng's study were similar with fluoxetine $\left(\chi^{2}=0.01, P=0.92\right),{ }^{50}$ while diazepam group

Table 3 Treatment-emergent adverse events of fluoxetine

\begin{tabular}{llll}
\hline $\begin{array}{l}\text { Adverse } \\
\text { events }\end{array}$ & $\begin{array}{l}\text { \% treated } \\
\text { with fluoxetine } \\
(\mathbf{n = 3 7 0 )}\end{array}$ & $\begin{array}{l}\text { Adverse } \\
\text { events }\end{array}$ & $\begin{array}{l}\text { \% treated } \\
\text { with fluoxetine } \\
(\mathbf{n}=\mathbf{3 7 0})\end{array}$ \\
\hline Dry mouth & 11.3 & Palpitation & 1.9 \\
Nausea & 11.0 & Headache & 1.9 \\
Insomnia & 6.2 & Somnolence & 1.9 \\
Drowsiness & 5.4 & Tremor & 1.9 \\
Constipation & 5.1 & Anorexia & 1.6 \\
Agitation & 4.3 & Sweating & 1.3 \\
Fatigue & 2.4 & Sexual problem & 0.5 \\
\hline
\end{tabular}

Note: Data were pooled from eleven studies of Chinese patients with GAD in fluoxetine arms.

Abbreviation: GAD, generalized anxiety disorder. in both studies had higher TESS scores than fluoxetine with statistically significant differences. ${ }^{48,49}$ In terms of comparing tricyclic antidepressants with fluoxetine, based on two Chinese studies, TCAs had significantly more adverse events and a less acceptable adverse effect profile. In He's study, the total adverse events of doxepine were 24, including three participants who had ECG changes during 4 weeks' treatment, while in fluoxetine group the number of adverse events was only five. ${ }^{51}$ In another study, amitriptyline's anticholinergic effects seemed to be worse: nearly $100 \%$ of participants had dry mouth, 79\% percent constipation, and 54\% tachycardia, but in fluoxetine, the proportion of these symptoms was $32 \%, 24 \%$, and $4 \%$, respectively. ${ }^{52}$

\section{Place of fluoxetine in the management of GAD in Chinese}

In the People's Republic of China, fluoxetine 20-60 mg daily has been studied in acute phase 4-8 week, openlabel, controlled head-to-head clinical trials and has shown significant efficacy with regard to improvement from baseline in the assessment of anxiety. The acting time of fluoxetine is relatively fast, within 1 or 2 weeks. In addition, fluoxetine was generally well-tolerated in short-term treatment with adverse events being of mild to moderate severity. However, no data is available on the long-term efficacy of fluoxetine in preventing relapse in responders and long-term adverse events as well as its impact on functional improvement in Chinese GAD patients. Although these head-to-head studies had demonstrated either equivalence or statistically significant difference in terms of efficacy and tolerability between fluoxetine and certain anxiolytics, given the high risk of bias of the included studies, overall small sample size, and no placebo control, as well as the lack of certain clinically meaningful outcomes, it is not possible to recommend fluoxetine as a reliable first-line treatment in Chinese patients with GAD and no definitive implications for clinical practice in choosing anxiolytics can be drawn. Trials comparing two active treatments with much larger sample sizes, better quality, and longer duration than the studies that we identified for this review and more clinically meaningful outcomes like quality of health, relapse prevention, adherence, patient perspective, and cost-effectiveness are needed in future research.

\section{Disclosure}

The authors report no conflicts of interest in this work. 


\section{References}

1. Kessler RC, DuPont RL, Berglund P, Wittchen HU. Impairment in pure and comorbid generalized anxiety disorder and major depression at 12 months in two national surveys. Am J Psychiatry. 1999;156(12): 1915-1923.

2. Ballenger JC, Davidson JR, Lecrubier Y, et al. Consensus statement on generalized anxiety disorder from the International Consensus Group on Depression and Anxiety. J Clin Psychiatry. 2001;62 Suppl 11:53-58.

3. American Psychiatric Association. Diagnostic and Statistical Manual of Mental Disorders, Fourth Edition, Text Revision. Washington, DC: American Psychiatric Association; 2000.

4. Wittchen HU. Generalized anxiety disorder: prevalence, burden, and cost to society. Depress Anxiety. 2002;16(4):162-171.

5. Grant BF, Hasin DS, Stinson FS, et al. Prevalence, correlates, co-morbidity, and comparative disability of DSM-IV generalized anxiety disorder in the USA: results from the National Epidemiologic Survey on Alcohol and Related Conditions. Psychol Med. 2005;35(12):1747-1759.

6. Wittchen HU, Jacobi F, Rehm J, et al. The size and burden of mental disorders and other disorders of the brain in Europe 2010. Eur Neuropsychopharmacol. 2011;21(9):655-679.

7. Hunt C, Issakidis C, Andrews G. DSM-IV generalized anxiety disorder in the Australian National Survey of Mental Health and Well-Being. Psychol Med. 2002;32(4):649-659.

8. Phillips MR, Zhang J, Shi Q, et al. Prevalence, treatment, and associated disability of mental disorders in four provinces in China during 2001-2005: an epidemiological survey. Lancet. 2009;373(9680): 2041-2053.

9. Ma X, Xiang YT, Cai ZJ, et al. Generalized anxiety disorder in China: prevalence, sociodemographic correlates, comorbidity, and suicide attempts. Perspect Psychiatr Care. 2009;45(2):119-127.

10. Lee S, Tsang A, Zhang MY, et al. Lifetime prevalence and inter-cohort variation in DSM-IV disorders in metropolitan China. Psychol Med. 2007;37(1):61-71.

11. Sun XL, Li KQ, Cui LJ, et al. Epidemiological survey on generalized anxiety disorder in 4 areas of Hebei province. J Clin Rehabil Tissue Eng Res. 2007;11(39):7842-7844.

12. Lee S, Tsang A, Chui H, Kwok K, Cheung E. A community epidemiological survey of generalized anxiety disorder in Hong Kong. Community Ment Health J. 2007;43(4):305-319.

13. Lee S, Ma YL, Tsang A, Kwok K. Generalized anxiety disorder with and without excessive worry in Hong Kong. Depress Anxiety. 2009;26(10):956-961.

14. He YL, Ma H, Zhang L, Liu ZN, Jia FJ, Zhang MY. A cross-sectional survey of the prevalence of depressive-anxiety disorders among general hospital outpatients in five cities in China. Zhonghua Nei Ke Za Zhi. 2009;48(9):748-751.

15. Ying DG, Jiang S, Yang H, Zhu S. Frequency of generalized anxiety disorder in Chinese primary care. Postgrad Med. 2010;122(4):32-38.

16. Chien IC, Chou YJ, Lin CH, Bih SH, Chou P. Prevalence of psychiatric disorders among National Health Insurance enrollees in Taiwan. Psychiatr Serv. 2004;55(6):691-697.

17. Wittchen HU, Zhao S, Kessler RC, Eaton WW. DSM-III-R generalized anxiety disorder in the National Comorbidity Survey. Arch Gen Psychiatry. 1994;51(5):355-364.

18. Lieb R, Becker E, Altamura C. The epidemiology of generalized anxiety disorder in Europe. Eur Neuropsychopharmacol. 2005;15(4): 445-452.

19. Bandelow B, Zohar J, Hollander E, et al. World Federation of Societies of Biological Psychiatry (WFSBP) guidelines for the pharmacological treatment of anxiety, obsessive-compulsive and post-traumatic stress disorders - first revision. World J Biol Psychiatry. 2008;9(4): 248-312.

20. National Collaborating Centre for Mental Health (UK). Generalized Anxiety Disorder in Adults: Management in Primary, Secondary and Community Care. Leicester, UK: British Psychological Society; 2011.
21. Hackett D, Haudiquet V, Salinas E. A method for controlling for a high placebo response rate in a comparison of venlafaxine $\mathrm{XR}$ and diazepam in the short-term treatment of patients with generalised anxiety disorder. Eur Psychiatry. 2003;18(4):182-187.

22. Chessick CA, Allen MH, Thase M, et al. Azapirones for generalized anxiety disorder. Cochrane Database Syst Rev. 2006;(3): CD006115.

23. Boschen MJ. A meta-analysis of the efficacy of pregabalin in the treatment of generalized anxiety disorder. Can J Psychiatry. 2011;56(9): $558-566$.

24. Kapczinski F, Lima MS, Souza JS, Schmitt R. Antidepressants for generalized anxiety disorder. Cochrane Database Syst Rev. 2003;(2): CD003592.

25. LaLonde CD, Van Lieshout RJ. Treating generalized anxiety disorder with second generation antipsychotics: a systematic review and metaanalysis. J Clin Psychopharmacol. 2011;31(3):326-333.

26. Guaiana G, Barbui C, Cipriani A. Hydroxyzine for generalised anxiety disorder. Cochrane Database Syst Rev. 2010;(12):CD006815.

27. Wu W, Wang G, Ball S, Desaiah D, Ang QQ. Duloxetine versus placebo in the treatment of patients with generalized anxiety disorder in China. Int J Neuropsychopharmacol. 2011;124(20):3260-3268.

28. Uzunova V, Sheline Y, Davis JM, et al. Increase in the cerebrospinal fluid content of neurosteroids in patients with unipolar major depression who are receiving fluoxetine or fluvoxamine. Proc Natl Acad Sci U SA. 1998;95(6):3239-3244.

29. Rasmusson AM, Pinna G, Paliwal P, et al. Decreased cerebrospinal fluid allopregnanolone levels in women with posttraumatic stress disorder. Biol Psychiatry. 2006;60(7):704-713.

30. Pinna G, Costa E, Guidotti A. Fluoxetine and norfluoxetine stereospecifically and selectively increase brain neurosteroid content at doses that are inactive on 5-HT reuptake. Psychopharmacology (Berl). 2006;186(3):362-372.

31. Pinna G, Dong E, Matsumoto K, Costa E, Guidotti A. In socially isolated mice, the reversal of brain allopregnanolone down-regulation mediates the anti-aggressive action of fluoxetine. Proc Natl Acad Sci U S A. 2003;100(4):2035-2040.

32. Pinna G, Costa E, Guidotti A. SSRIs act as selective brain steroidogenic stimulants (SBSSs) at low doses that are inactive on 5-HT reuptake. Curr Opin Pharmacol. 2009;9(1):24-30.

33. Lohoff FW, Aquino TD, Narasimhan S, Multani PK, Etemad B, Rickels K. Serotonin receptor 2A (HTR2A) gene polymorphism predicts treatment response to venlafaxine XR in generalized anxiety disorder. Pharmacogenomics J. 2013;13(1):21-26.

34. Porcelli S, Fabbri C, Serretti A. Meta-analysis of serotonin transporter gene promoter polymorphism (5-HTTLPR) association with antidepressant efficacy. Eur Neuropsychopharmacol. 2012;22(4): $239-258$.

35. Smits KM, Smits LJ, Schouten JS, Stelma FF, Nelemans P, Prins MH. Influence of SERTPR and STin2 in the serotonin transporter gene on the effect of selective serotonin reuptake inhibitors in depression: a systematic review. Mol Psychiatry. 2004;9(5):433-441.

36. You JS, Hu SY, Chen B, Zhang HG. Serotonin transporter and tryptophan hydroxylase gene polymorphisms in Chinese patients with generalized anxiety disorder. Psychiatr Genet. 2005;15(1):7-11.

37. Roy-Byrne PP, Perera P, Pitts CD, Christi JA. Paroxetine response and tolerability among ethnic minority patients with mood or anxiety disorders: a pooled analysis. J Clin Psychiatry. 2005;66(10):1228-1233.

38. Kurose K, Sugiyama E, Saito Y. Population differences in major functional polymorphisms of pharmacokinetics/pharmacodynamicsrelated genes in Eastern Asians and Europeans: implications in the clinical trials for novel drug development. Drug Metab Pharmacokinet. 2012;27(1):9-54.

39. Yin SJ, Ni YB, Wang SM, Wang X, Lou YQ, Zhang GL. Differences in genotype and allele frequency distributions of polymorphic drug metabolizing enzymes CYP2C19 and CYP2D6 in mainland Chinese Mongolian, Hui and Han populations. J Clin Pharm Ther. 2012;37(3):364-369. 
40. Bradford LD. CYP2D6 allele frequency in European Caucasians, Asians, Africans and their descendants. Pharmacogenomics. 2002;3(2): 229-243.

41. Liu ZQ, Cheng ZN, Huang SL, et al. Effect of the CYP2C19 oxidation polymorphism on fluoxetine metabolism in Chinese healthy subjects. Br J Clin Pharmacol. 2001;52(1):96-99.

42. Liu ZQ, Shu Y, Huang SL, Wang LS, He N, Zhou HH. Effects of CYP2C19 genotype and CYP2C9 on fluoxetine N-demethylation in human liver microsomes. Acta Pharmacol Sin. 2001;22(1):85-90.

43. Li G. Comparative study of escitalopram and fluoxetine in treatment of generalized anxiety disorder. Chinese Modern Medicine And Drug. 2011;27(9):1287-1289.

44. Shao GY. Comparative study of escitalopram and fluoxetine in the treatment of general anxiety disorder (GAD). China Journal of Health Psychology. 2013;21(3):327-328.

45. Tang K, Ye QH, Chen ZB, et al. Clinical controlled observation on generalized anxiety disorder treated by duloxetine and fluoxetine tablets. Medical Journal of Chinese People's Health. 2012;24(1):60-61.

46. Kim TS, Pae CU, Yoon SJ, et al. Comparison of venlafaxine extended release versus paroxetine for treatment of patients with generalized anxiety disorder. Psychiatry Clin Neurosci. 2006;60(3):347-351.

47. Bose A, Korotzer A, Gommoll C, Li D. Randomized placebo-controlled trial of escitalopram and venlafaxine XR in the treatment of generalized anxiety disorder. Depress Anxiety. 2008;25(10):854-861.

48. Sun JZ, Wang SJ, Sun TX. A comparative study of fluoxetine and diazepam in the treatment of generalized anxiety disorder. Sichuan Psychological Health. 2000;13(4):253-254.

49. Liu XC, Chen YX, Shu RH. A comparative study of fluoxetine and diazepam in the treatment of patients with generalized anxiety disorder. Chinese Journal of Behavioral Medical Science. 2004;13(3): 282-283.

50. Peng L, Wu D, Tu J. A comparative study of fluoxetine and alprazolam in the treatment of generalized anxiety disorder. China Modern Doctor. 2012;50(31):78-79.

51. He Q, Xiao PX, Zhang GC, Zhang CH. Comparative and double-blinded study of doxepine and fluoxetine in treatment of generalized anxiety disorder in 64 patients. Shandong Medicine and Drugs. 2001;41(4):27-28.

52. Xu JX, Tan JW, Qu LM. Comparison of the effect of fluoxetine and amitriptyline in treating comorbid depression disorder and anxiety disorder. Chinese Journal of Clinical Rehabilitation. 2004;8(15):2812-2814.

53. Chen ZL, Hu JM. Effect analysis of fluoxetine in treating 55 patients with generalized anxiety disorder. Chinese Journal of Ethnomedicine and Ethnopharmacy. 2010;19(14):169-170.
54. Niu FR, Shen XH, Sun ST. Comparison of efficacy of mirtazapine and fluoxetine in treatment of depression with generalized anxiety disorder in 35 patients each. Chinese Journal of New Drugs and Clinical Remedy. 2004;23(12):853-855.

55. Wu FC, Li H, Huang XJ. Clinical study of bupropion hydrochloride sustained-release tablets for GAD patients. Guide Of China Medicine. 2012;10(21):114-116.

56. Tu GH. Comparative study of Deanxit and fluoxetine in treatment of generalized anxiety disorder. Medical Journal of Chinese People's Health. 2010;22(5):554-555.

57. Zhen HB, Deng HH, Zhang JP. Comparative study of buspirone and fluoxetine in treatment of generalized anxiety disorder. Chinese Journal of Neuropsychotic Disease. 1998;24(4):238-239.

58. Pollack MH, Kornstein SG, Spann ME, Crits-Christoph P, Raskin J, Russell JM. Early improvement during duloxetine treatment of generalized anxiety disorder predicts response and remission at endpoint. J Psychiatr Res. 2008;42(14):1176-1184.

59. Ma JS, Yu JL. Once-weekly dosing of fluoxetine in the maintenance treatment of generalized anxiety disorder. J Clin Psychol Med. 2002;12(2):82-83.

60. Burke WJ, McArthur-Miller DA. Exploring treatment alternatives: weekly dosing of fluoxetine for the continuation phase of major depressive disorder. J Clin Psychiatry. 2001;62 Suppl 22:38-42.

61. Emmanuel NP, Ware MR, Brawman-Mintzer O, Ballenger JC, Lydiard RB. Once-weekly dosing of fluoxetine in the maintenance of remission in panic disorder. J Clin Psychiatry. 1999;60(5): 299-301.

62. Schmidt ME, Fava M, Robinson JM, Judge R. The efficacy and safety of a new enteric-coated formulation of fluoxetine given once weekly during the continuation treatment of major depressive disorder. $J$ Clin Psychiatry. 2000;61(11):851-857.

63. Wu Z, Chen J, Yuan C, et al. Difference in remission in a Chinese population with anxious versus nonanxious treatment-resistant depression: a report of OPERATION study. J Affect Disord. 2013;150(3): 834-839.

64. Silverstone PH, Salinas E. Efficacy of venlafaxine extended release in patients with major depressive disorder and comorbid generalized anxiety disorder. J Clin Psychiatry. 2001;62(7):523-529.

65. Liu ZL, Wang LM, Liu J, Xiao SH. Effect and safety of the treatment for comorbid anxiety and depression by use of short-term and low-dose olanzapine in combination with fluoxetine. Chinese Journal of Clinical Rehabilitation. 2005;9(36):6-8.
Neuropsychiatric Disease and Treatment

\section{Publish your work in this journal}

Neuropsychiatric Disease and Treatment is an international, peerreviewed journal of clinical therapeutics and pharmacology focusing on concise rapid reporting of clinical or pre-clinical studies on a range of neuropsychiatric and neurological disorders. This journal is indexed on PubMed Central, the 'PsycINFO' database and CAS.

\section{Dovepress}

The manuscript management system is completely online and includes a very quick and fair peer-review system, which is all easy to use. Visit http://www.dovepress.com/testimonials.php to read real quotes from published authors. 